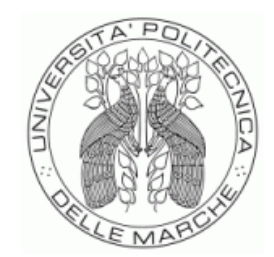

UNIVERSTTÀ POLITECNICADEUE MARCHE DIPARTIMENTO DI ECONOMIA

\title{
RE-DEFINING THE BOUNDARIES OF MAJOR ITALIAN CITIES
}

\author{
Antonio G. Calafati And PaOlo Veneri
}

WORKING PAPER n. 342 
A.G. Calafati and P. Veneri, Re-defining the Boundaries of Major Italian Cities.

Comitato scientifico:

Renato Balducci

Marco Crivellini

Marco Gallegati

Alberto Niccoli

Alberto Zazzaro

Collana curata da:

Massimo Tamberi

\section{Autori:}

\section{Antonio G. Calafati}

Università Politecnica delle Marche

Dipartimento di Economia

P.le Martelli, 8

60121 Ancona, Italy

Web site: http://www.antoniocalafati.it

e-mail: $\quad$ a.g.calafati@univpm.it

\section{Paolo Veneri}

Università Politecnica delle Marche

Dipartimento di Economia

P.le Martelli, 8

60121 Ancona, Italy

e-mail: $\quad$ p.veneri@univpm.it

\section{Copyright (Antonio G. Calafati \& Paolo Veneri}




\begin{abstract}
The processes of spatial polarisation and territorial integration that have taken place in Italy since the 1950s have not been accompanied by corresponding institutional adaptations, generating the current huge discrepancy between the functional and political-administrative organisation of the territory. As argued in the paper, this institutional lock-in is rooted in a mistaken conceptualisation of territorial integration, which has focused on the identification of 'travel-towork areas', rather than on the formation of inter-municipal territorial systems which have the nature of cities de facto - larger and structurally different from the legal cities. The paper corroborates this thesis by focusing on the eight largest Italian cities de jure, identifying, on the basis of both functional and morphological features, the corresponding cities de facto.
\end{abstract}

Keywords: Cities de facto, Metropolitan areas, Territorial organisation

JEL Classifications: R11, R12, R23, R38 
A.G. Calafati and P. Veneri, Re-defining the Boundaries of Major Italian Cities. 


\section{Introduction ${ }^{*}$}

A deep and widespread discrepancy between the political-administrative and functional organisation of territory characterises contemporary Italy. It has been generated by what may be called 'territorial coalescence without institutional coalescence'. In fact, the intense processes of spatial polarisation and territorial integration that have taken place since the 1950s have not been accompanied by corresponding institutional adaptations. The spatial organisation of the political-administrative system has not been changed, nor have consistent forms of governance for the emerging functional areas been introduced. As a consequence, for some decades, the local policy-making process has been shaped in Italy by a configuration of norms that does not at all reflect the spatiality of social and economic structures - norms that in the language of Thorsten Veblen may be regarded as 'ceremonial', i.e. ones not serving but hampering economic development.

The aim of this paper is to verify, in the cases of the eight largest Italian cities (Rome, Milan, Turin, Florence, Bologna, Naples, Palermo, Genoa), the existence of inter-municipal territorial systems that may qualify as cities de facto and to identify their boundaries. We shall argue that the cities examined which are the key territorial actors of the Italian economy - have coalesced with a set of contiguous municipalities. These municipalities are comparatively 'very small' and 'very close' to the focal points of corresponding pivot (legal) cities. Taken together with the corresponding pivot cities these sets of contiguous municipalities form inter-municipal territorial systems which ought to be interpreted as the new Italian metropolises - and as such they ought to be governed. ${ }^{1}$

The lock-in in the evolution of the institutions shaping the local policymaking process generated the current huge discrepancy between the functional and political-administrative organisation of the territory. This lock-in, which does not allow the Italian territory to be consistently governed, is rooted in the mistaken conceptualisation of territorial integration that has prevailed. To date, the analytical focus has been on the identification of 'functional urban regions' (FUR), whereas the fundamental outcome of territorial coalescence as manifest in Italy, namely the formation of inter-municipal urban systems which are cities de facto, has remained unaddressed.

If a clear distinction had been drawn between the 'formation of cities de facto' and the formation of 'functional urban regions', it would have become evident that a further critical distinction had to be drawn between, on the one

\footnotetext{
* A preliminary version of the paper was presented at the Regional Studies Association Annual International Conference 2010 (Pécs, Hungary, May 24-26).

1 Although this paper focuses on the 8 largest Italian cities, it should not be forgotten that territorial coalescence has been a widespread phenomenon involving practically the entire Italian territory.
} 
hand, expanding the boundaries of cities de jure (to make them overlap with cities de facto) and, on the other, designing appropriate governance schemes for functional urban regions. While some attempts have been made in order to recognise, by law, metropolitan areas, they all practically failed and the bulk of governmental power remained to municipalities, which nowadays have very strong political power, compared with other countries in Europe (European Commission, 2007 - Ch. 5). The scientific debate failed to recognize that removing the institutional lock-in that characterises Italy - 8,101 municipalities with equal political-administrative powers - made it necessary, against the background of the profound territorial transformation experienced in Italy in recent decades, to address the questions of (a) identifying cities de facto and (b) transforming those cities de facto into the new Italian (legal) cities.

The paper is organised as follows. Section 2 deals with the main interpretations of territorial coalescence put forward in Italy. Section 3 focuses on the lock-in that has characterised Italy with regard to its regional governance mechanisms. Section 4 proposes a new perspective on the Italian territory, and in particular suggests distinguishing 'cities de facto' from 'functional urban areas' in the conceptualisation of the territory. Section 5 puts forward our hypothesis about the cities de facto corresponding to the eight largest Italian cities, on which the analysis is focused. Section 6 discusses the empirical evidence with which to corroborate the hypothesis advanced in the previous section. Finally, section 7 makes some concluding remarks.

\section{Interpreting territorial coalescence in Italy}

How the new territorial organisation of society should be conceptualised has been a question debated in the Italian scientific community since the 1970 s. $^{2}$ The implications of territorial integration for the suitability of the rules shaping regional policy-making processes have also been addressed. Yet the positive and normative analyses conducted to date have not cross-bred. And after five decades of profound territorial transformation - so profound as to be unparalleled in Europe - Italy still lacks both a shared spatial conceptualisation of its territory and a scheme for reform of the policy-making process consistent with the new territorial patterns of integration.

The Italian industrial take-off in the decades between 1950 and 1980, and the ensuing large redistribution and concentration of population and employment, brought about an extraordinary change in the spatial organisation of the economic and social process. It led to 'territorial integration': the formation of new functional clusters of contiguous municipalities. This process started to attract scientific attention in the mid-1970s, especially in relation to the 'industrial districts question'. In fact, industrial districts have been conceptualised in the Italian economic literature as socio-economic structures

${ }^{2}$ See Calafati (2009b) for a recent survey of the scientific debate on this question. 
which, in practice, have invariably taken the form of inter-municipal territorial systems. ${ }^{3}$

Stimulated by the emerging research programme of the 'economics of local development' (very influential in Italy), which focuses on the trajectories of inter-municipal territories, already in the late 1980s the Italian Statistical Office (ISTAT) addressed the issue of territorial coalescence by drawing up a map of Italy in terms of 'functional areas' (ISTAT-IRPET, 1989). This map, which ISTAT updated twice in the subsequent decades (ISTAT, 1997; 2005), established a new way to conceptualise the Italian territory that seemed to solve the problem of accounting for the widespread phenomenon of territorial coalescence. The elementary units of this map consist by definition - given the nature of the algorithm used (ISTAT-IRPET, 1989) - of 'functional areas' which are invariably 'clusters of contiguous municipalities'. These are referred to in the literature as 'local labour systems' (LLSs) - because the key information used by the algorithm to generate them consists in data on travelto-work commuting. ${ }^{4}$ There may be only a few or very many municipalities making up each cluster. In the case of the cities examined here, their numbers range from 14 units (Naples) to 115 units (Milan).

The map of LLSs drawn by ISTAT was extensively used. A large number of territorial comparative studies were conducted adopting LLSs as units of analysis, this being the case of most comparative studies on industrial districts'. Indeed, the ISTAT's approach to the question was notable for its success in making available a map in terms of functional areas with regard to the whole Italian territory. It captured the phenomenon of territorial integration wherever it had manifested itself, whether in remote mountain territories or in the most densely populated industrial areas. Yet it was not the only significant attempt made to capture the phenomenon of territorial integration. Another noteworthy line of analysis on territorial integration in Italy sought to identify another type of 'functional area', namely the 'metropolitan area'.

The first notable work in this strand of the Italian literature was that by Cafiero and Busca (1970), who identified 32 metropolitan areas on the basis of morphological criteria like absolute population, employment, and residential density thresholds for a set of contiguous municipalities. Two decades later, Cecchini (1988) and Bartaletti (1992) used similar criteria to identify 39 and 29 metropolitan areas respectively. Other identification exercises, again conducted from a morphological perspective, were those by Vitali (1990) and Marchese (1997). The latter, besides considering density thresholds, selected contiguous

\footnotetext{
${ }^{3}$ See Becattini (1979) and Calafati (2002; 2009a) for a reconstruction of the process that led in Italy to the focus on the inter-municipal unit of analysis in the study of local development. For a recent survey on this topic, see Compagnucci (2009).

4 The first map identified 995 'clusters of municipalities' (named Local Labour Systems (LLSs), i.e. basically labour-market areas maximizing the auto-containment of commuting flows) using data on commuting in 1981. The other two maps have been successively drawn up using commuting data in 1991 and 2001 (with the result of 784 and 686 LLSs respectively). For a critique of Local Labour Systems, see Calafati (2005).

${ }^{5}$ See, among many others, Cainelli et al. (2006) and Signorini (2000).
} 
municipalities providing crucial factors such as, for example, high rank services. In a recent work, Boix and Veneri (2009) have made a further attempt to identify Italian metropolitan areas by applying the Functional Urban Region's (FUR) algorithm of Gemaca II (Brunel, 2002) and a new specification of the algorithm proposed by the U.S. Federal Register (Office of Management and Budget, 1990), generating the so-called 'Dynamic Metropolitan Area' (DMA). Recently, the Italian Central Statistical Office (ISTAT, 2008) has proposed a map of Italy drawn in terms of 'metropolitan regions'. Up to 41 'metropolitan regions' are proposed, each conceived as a cluster of previously identified 'local labour systems' (according to ISTAT’s 2005 map).

The analysis of territorial integration has become an important concern of Italian regional studies in recent decades. The resulting conceptualisations of the Italian territory in terms of 'inter-municipal local systems' (or 'intermunicipal functional areas') have gained scientific recognition, and they have been extensively used to conduct comparative analyses of local economic performances. Nevertheless, contrary to what one might expect, these conceptualisations have had no impact on the spatial organisation of the policy-making process.

\section{An institutional lock-in}

Notwithstanding acknowledgement of territorial coalescence as a critical phenomenon - and a widespread scientific debate on inter-municipal planning - the spatial organisation of the Italian policy-making process has not undergone any major revision. Firstly, metropolitan areas have not been established as 'policy units'; secondly, the administrative boundaries of the Italian cities, which date back to the early nineteenth century (Ferlaino and Molinari, 2009), have remained unchanged; thirdly, no stable re-allocation of political power among municipalities and inter-municipal coalitions has been accomplished. The straightforward consequence of this institutional lock-in is that the functional organisation of the Italian territory, at least since the mid1970s, no longer matches the spatial structure of the policy-making process.

Although without any practical effect, the question of 'institutional coalescence' as a response to 'territorial coalescence' received significant political recognition in Italy with law no. 142/1990 - which promised to be a turning point in the country's political-administrative history and which has been followed by other laws issued during the 1990s and the 2000s. ${ }^{6}$ With

\footnotetext{
6 The law no. 142/1990 was followed by other laws, in which a better and more coherent identification of the 'powers' of metropolitan areas were stated: law no. 112/1998, law no. $265 / 1999$, law no. $267 / 2000$ and law no. 42/2009. It should be clearly stressed, however, that these laws did not institute 'metropolitan areas' but rather they established the legal framework within which 'metropolitan areas' could be generated by the 'concerned' municipalities. Moreover, these laws did not identified the boundaries of metropolitan areas but only the Italian cities to which a metropolitan areas as governance mechanisms could be associated.
} 
regard to the spatial organisation of the policy-making process, these laws were intended to pave the way to a number of meta-institutional changes of critical importance. On the one hand, nine potential metropolitan areas were identified $^{7}$ (Turin Milan, Venice, Genoa, Bologna, Florence, Rome, Bari, Naples). On the other hand, a number of legal instruments were introduced to grant political power to new political-administrative units. Such institutional change was supposed take the form of binding agreements on strategic issues or complete institutional integration (mergers) among contiguous municipalities.

However, law makes no reference to the possible boundaries of metropolitan areas and, more importantly, it assigns just coordination powers to them, instead of substituting municipalities in their own more important powers. As a consequence, new metropolitan areas, even once identified and constituted, would take almost the same functions of the already existing provinces (NUTS-3). In addition, these legislative attempts interpreted institutional coalescence as a bottom-up process, hence making very difficult to realise a real re-distribution of power from the too small municipalities to the new political-administrative units (e.g. metropolitan areas).

This set of laws implicitly raised two quite different policy questions: firstly, formal acknowledgement of metropolitan areas by granting them political power - in particular, in strategic spatial planning; secondly, acknowledgement of the cities de facto made up of clusters of contiguous municipalities - these being the starting points from which to form political coalitions or move on to mergers of contiguous municipalities. Two scientific questions were associated with these two policy questions. On the one hand, endowing metropolitan areas with a governance mechanism would first require their identification. ${ }^{9}$ On the other hand, posing the question of incorporations and mergers with reference to inter-municipal territorial units would have required the identification, at least in the most notable instances, of the cities de facto generated by territorial coalescence. ${ }^{10}$

\footnotetext{
7 These nine metropolitan areas were later confirmed by the d.lgs. no. 267/2000. In addition, Sicily, Sardinian and Friuli-Venezia Giulia, which are regions endowed with 'a special status' in Italy, have introduced, through regional laws, other five metropolitan areas: Catania, Messina and Palermo (law no. 9/1986), Cagliari (law no. 4/1997), Trieste (law no. 10/1988).

${ }^{8}$ In particular, the d.lgs. no. $267 / 2000$, apart from confirming metropolitan areas as potential inter-municipal governance mechanisms, improved the legal framework to establish three other minor forms of inter-municipal governance - that had already been introduced in the $\mathrm{L}$. 142/1990: "Convenzioni", "Consorzi", "Unioni dei Comuni" and "Accordi di programma". As a consequence there are nowadays many instances of inter-municipal governance systems, but their impact is negligible, with only a very small share of the population involved and only minor types of public issues addressed.

9 The answer could possibly converge towards a specific proposal, after taking into consideration, case by case, the identification exercises discussed in the previous section.

10 See, among other contributions, the following: Costa and Toniolo (1992); Camagni and Lombardo (1999); Martinotti (1999). To be noted is that the debate on the disequilibria and most appropriate governance mechanisms of the Italian metropolitan areas remained separate from the question of their practical identification.
} 
The question of identifying metropolitan areas persisted in the Italian scientific debate, although in the end it attracted less attention, and no effort was made by the scientific community to produce a shared map. Moreover, the debate on the structure and governance of metropolitan areas remained separate from that on their concrete identification. By contrast, the question of identifying the cities de facto has never been high on the scientific and policy agenda

This complete lack of interest in the city de facto to be observed in the Italian debate on territory and territorial transformation is rather surprising when viewed against the background of European urban history in the past century. In Germany, to provide an example that may be relevant to Italy, the expanding boundaries of cities have been closely monitored, and the incorporation (Eingemeindung) of contiguous municipalities by large, growing cities has been common practice since the country began its industrialisation trajectory. Munich, which has expanded from 1,500 to 30,000 ha. by progressively incorporating a number of contiguous municipalities (Zimmerman 2004, pp. 119-127) may be an exceptional case, but the practice of incorporation has been widespread. Moreover, in order to deal with the changing organisation of the territory, Germany has changed the allocation of power among different territorial units (Gemeinde vs. Kreis) on the basis of a distinction between 'administration' and 'government'. Indeed, from a European perspective (Ferlaino and Molinari, 2009) the Italian institutional lock-in is a notable exception (cf. for a recent proposal Calafati, 2009, chap. V)

Removing this institutional lock-in would have important effects in Italy. As we shall see in the following section, cities de facto are significantly larger in terms of population and territory than cities de jure. Therefore, making cities de jure overlap with cities de facto would have two fundamental consequences. It would lead to: a) a different policy agenda - different items and above all a different hierarchy of objectives; b) a different "space of effects" in the evaluation of alternative collective choices, determining different allocations of surplus.

In order to appreciate the importance of turning cities de facto into cities de jure one should consider, in addition to the number of municipalities involved and the extension of the territory affected, that the 'power' of Italian municipalities is very strong. Already significant in 1950s, in particular in the field of spatial planning - which directly affects the evolution of the spatial organisation of social and economic processes - it has steadily increased in the past decade. Indeed, Italian municipalities, even the very small ones, and regardless of whether they govern marginal territories in mountain areas or important residential and industrial settlements on the outskirts of large cities, are nowadays among those endowed with the strongest political power in Europe (European Union, 2007, Ch. 5). The current state of affairs is such that one observes a marked power fragmentation - and territorial competition within Italian 'functional urban areas', and, more importantly, also within 
territories so closely integrated spatially and relationally as to be indistinguishable.

\section{The identification of Italy's cities de facto: the hypothesis}

Practically all clustering procedures applied in Italy for the identification of 'functional areas' share the same weakness: the inner territorial organisation of the functional areas identified (local systems) is not explicitly examined and discussed. The remarkable differences in the degree of territorial integration to be found in any cluster are not explored, and they play no role in the conceptualisation of coalescence processes. Analysing the inner territorial integration of functional urban areas would instead be necessary, given the nature of clustering procedures. In fact, by definition they generate clusters that may comprise municipalities with very different degrees of integration with each another (including the pivot cities). This point was overlooked in the scientific discussion, and the 'functional areas' identified (ISTAT's LLS or metropolitan areas) have been used without any reference to the fact that a sub-set of the municipalities making up a given 'functional area' may have a particularly high degree of integration. Contiguous municipalities - as has so often happened in urban history - may not simply 'integrate' with one another; rather, they 'melt into' each other, generating what, according to our interpretation, are new cities.

The clustering procedures leading to identification of the 'functional areas' of the Italian territory has taken the pivotal units for granted. The territories around them have been scanned to assess whether the degree of integration with the pivotal cities is above a given threshold, ${ }^{11}$ but the information gathered by means of this scanning process has not been used to question the appropriateness of the legal boundaries of the pivotal units. It has not been realized that, when searching for the 'functional urban areas' corresponding to Italian cities it is necessary to deal with the issue of the suitability of cities' legal boundaries.

In this paper we suggest that an appropriate strategy with which to conceptualise the Italian territory would be to shift from Fig. 1a to Fig. 1b, which refer to two different why-questions. When identifying a functional urban area, it should not be taken for granted - as has happened to date in Italy - that its core ('pivot') is the corresponding legal city (Fig. 1.a). Instead, it should be borne in mind that the core may comprise a cluster of municipalities that, according to our interpretation, qualifies as the new city de facto (Fig 1b). ${ }^{12}$

\footnotetext{
11 The nature of internal integration has also been discussed, these two perspectives making it possible to address the question of the potential polycentricity of the metropolitan areas. See Veneri (2009) for an analysis on this topic.

12 The inner territorial organisation of Italian local systems has not been researched. As a way to simplify the analysis, the largest local systems have been interpreted as 'urban systems' and
} 
Cities de facto are spatial and relational facts. Yet they can no longer be spatially identified with 'built cities' (Parr, 2007a). Indeed, contemporary Italian cities de facto are dispersed cities that have emerged from processes of territorial coalescence between a pivotal city and its neighbouring municipalities located in the rings. Italian large cities - once correctly identified spatially - are 'dispersed' cities, as are practically all European metropolises. Since Geddes (1915) introduced the categories of 'conurbation', the shift from the 'compact' to the 'dispersed' spatial organisation of metropolises has become a central issue in urban studies. ${ }^{13}$ What the Italian debate has failed to acknowledge is that the emphasis on the relational dimension of cities - and the acceptance of their dispersed nature - would have required redefining cities' boundaries and reshaping their political-administrative systems. In fact, when considering territorial development, one should distinguish between two different phenomena: on the one hand, the expansion of cities in space; on the other, the formation of larger functional urban areas.

Figure 1 - The inner organisation of Italian local systems

Figure 1.a

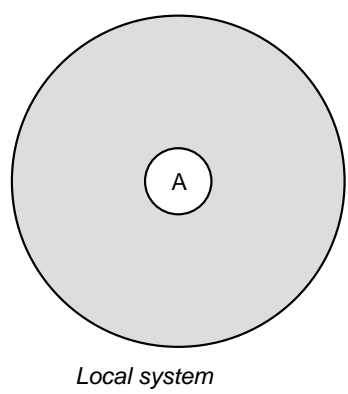

A: Pivot (legal) city
Figure 1.b

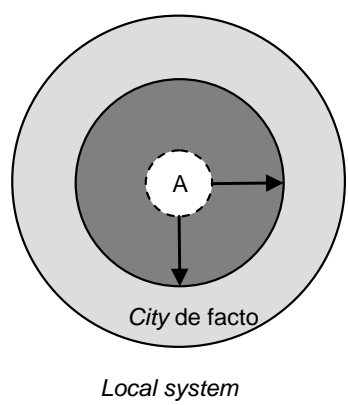

Figure 2 proposes a very simple representation of the different spatial aggregates to which reference is usually made when discussing the functional organisation of the territory. Starting from the pivotal municipality - the legal city, in the case of Italy - which is located at the origin of the axes, and which is the most elementary spatial unit with the data available, the further one moves outwards the more the degree of integration between municipalities and their corresponding pivots decreases. We may imagine that there exists a

comparative analysis conducted on the basis of these objects (Istat, 1997; Calafati and Mazzoni, 2008; Costa and Toniolo, 1992).

13 The changing organisation of metropolises has also changed the conceptualisation of 'megalopolis' (Lang, Knox 2009) 
threshold, associated with a certain distance, in the degree of integration between the core and its surrounding municipalities that identifies the city de facto.

Figure 2 Different spatial levels of cities

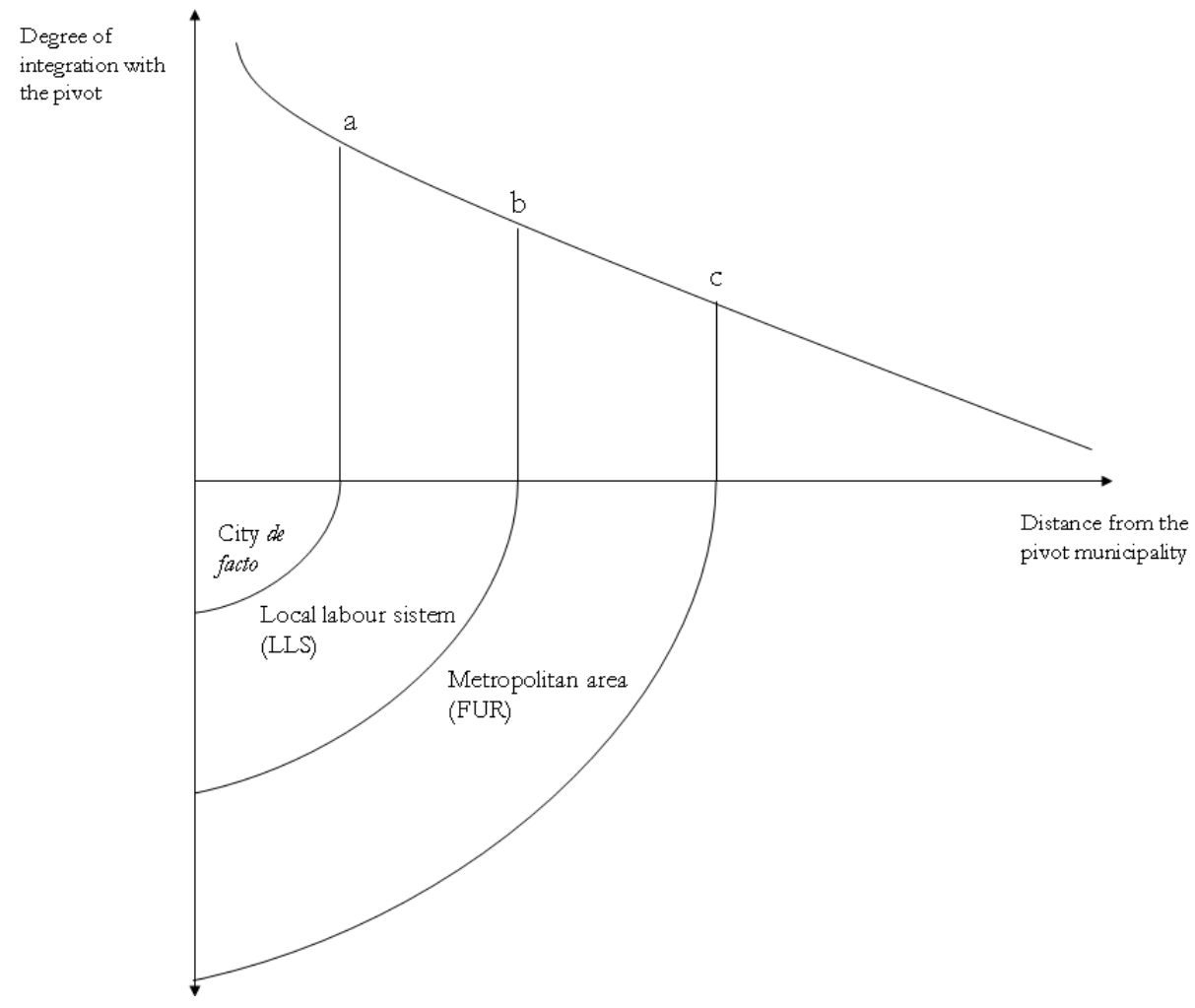

Point ' $a$ ' in Figure 2 indicates a threshold in the degree of integration between each pivot and its corresponding ring municipalities that identifies the city de facto. Below this threshold, the degree of integration is very strong and related to the typical interactions that take place within a single contemporary city. At this level, both functional and morphological integration play a significant role. Above this threshold, the city de facto ends, but we are still in the same travel-to-work area - which in Italy can be approximated with the LLS. In a similar way, Parr (2007a) would call this spatial aggregate an 'Employment City'. More distant from the centre, point ' $\mathrm{b}$ ' marks the end of the LLS, which is only one part of a wider metropolitan area (FUR). A further functional unit, the city-region, could be added for particularly wide metropolitan contexts (Hall, 2009; Parr, 2008).

Construing the outcome of territorial coalescence in terms of the elementary categories of regional studies, such as 'city', 'travel-to-work area', 
'metropolitan area', 'city-region' and the like, is certainly not straightforward. The conceptual and practical difficulties of identifying different territorial units have been constant matters of reflection (see for recent discussion of the issue Parr (2007a; 2007b; 2008), who has proposed a general framework to distinguish among different forms of territorial integration). These difficulties reflect the more general, well-known difficulty of identifying the boundaries of any complex system (Waddington, 1977).

If the issue is approached from a pragmatic perspective, the identification of the cities de facto generated by trajectories of spatial and relational development might prove to be an exercise with a straightforward solution. We put forward the hypothesis that the municipalities located in the first and second rings are so closely integrated - in relational and spatial terms - with the corresponding pivotal cities that, taken together, they constitute the new Italian cities. These are the new cities de facto to be turned into cities de jure, thus restoring a correspondence between functional and administrative structures.

\section{Identifying the Italian new cities: setting the empirical context}

Against the background of the debate on the functional organisation of the Italian territory, let us now focus on six types of territorial units which seem relevant to setting the context for identification of the new boundaries of the Italian cities (see Table 1 and Fig. 3): a) the legal city; b) the legal city plus the first ring of municipalities; c) the legal city plus the first and second rings of municipalities $^{14}$; d) the local system identified by ISTAT (LLS); e) the Province (NUTS-3); f) the metropolitan area (FUR).

Territorial units (a) and (e) have a 'legal status' that characterises them as levels of government in the Italian political system; territorial units (d) and (f) have a functional status in the way they have been identified, but no level of governance corresponds to them. ${ }^{15}$ Territorial units (b) and (c) have not attracted any attention, being considered part of the corresponding 'functional urban areas' (LLSs) - whereas, as we maintain in this paper, they can approximate the city de facto.

\footnotetext{
${ }^{14}$ In order to narrow the analysis to the municipalities with a strong functional integration with the pivot, only those that are also included in the same LLS have been taken into consideration. Indeed, in the complex geography of Italian territory it may happen that municipalities that are contiguous belong to different territorial systems.

15 In some cases - the most notable being possibly that of Turin - attempts to establish a 'weak' and project-specific governance mechanism at the level of metropolitan areas has been made in the process of strategic planning of some Italian cities. With practically no results. Nevertheless, the scientific discussion on inter-municipal governance mechanism has been very wide in Italy.
} 
Tab. 1a - Major Italian Cities and their Territorial Organisation

\begin{tabular}{|c|c|c|c|c|c|c|c|c|c|c|c|}
\hline & $\begin{array}{r}\text { Main } \\
\text { municipality } \\
\text { (a) }\end{array}$ & $\begin{array}{r}\text { (a) }+1^{\text {st }} \text { ring mu } \\
\text { (b) }\end{array}$ & $\begin{array}{l}\text { cip. } \\
\text { n.* }\end{array}$ & $\begin{array}{r}\text { (b) }+2^{\text {nd }} \text { ring mu } \\
\text { (c) }\end{array}$ & $\begin{array}{l}\text { ic. } \\
\text { n. }\end{array}$ & $\begin{array}{l}\text { LLS } \\
\qquad \text { (d) }\end{array}$ & n. & $\begin{array}{r}\text { NUTS3 } \\
\text { (e) }\end{array}$ & n. & $\begin{array}{l}\text { MA } \\
\text { (f) }\end{array}$ & n. \\
\hline \multicolumn{12}{|c|}{ Population } \\
\hline Turin & 865,263 & 1269725 & 14 & 1485146 & 38 & $1,684,336$ & 88 & $2,165,619$ & 315 & $2,000,018$ & 215 \\
\hline Milan & $1,256,211$ & $1,852,320$ & 22 & $2,416,471$ & 45 & $2,975,754$ & 115 & $3,707,210$ & 189 & $5,249,727$ & 499 \\
\hline Bologna & 371,217 & 540,013 & 10 & 645,448 & 21 & 723,366 & 32 & 915,225 & 60 & 907,764 & 56 \\
\hline Florence & 356,118 & 543,511 & 6 & 654,411 & 14 & 677,196 & 19 & 933,860 & 44 & $1,197,190$ & 51 \\
\hline Rome & $2,546,804$ & $3,113,130$ & 29 & $3,294,292$ & 51 & $3,374,511$ & 70 & $3,700,424$ & 122 & $4,338,854$ & 239 \\
\hline Genoa & 610,307 & 672,376 & 13 & 716,760 & 24 & 723,633 & 32 & 878,082 & 67 & 122,888 & 20 \\
\hline Naples & $1,004,500$ & $1,556,532$ & 14 & $2,009,307$ & 27 & $2,235,602$ & 37 & $3,059,196$ & 92 & $3,512,698$ & 125 \\
\hline Palermo & 686,722 & 789,357 & 7 & 844,564 & 14 & 856,152 & 17 & $1,235,923$ & 82 & $1,062,993$ & 43 \\
\hline \multicolumn{12}{|c|}{ Employment } \\
\hline Turin & 412,067 & 576,848 & 14 & 660,406 & 38 & 724,413 & 88 & 887,085 & 315 & 826,479 & 215 \\
\hline Milan & 808,642 & $1,093,324$ & 22 & $1,318,406$ & 45 & $1,541,171$ & 115 & $1,790,042$ & 189 & $2,390,954$ & 499 \\
\hline Bologna & 206,088 & 298,861 & 10 & 350,478 & 21 & 375,157 & 32 & 446,451 & 60 & 442,561 & 56 \\
\hline Florence & 199,678 & 276,074 & 6 & 315,109 & 14 & 323,441 & 19 & 417,896 & 44 & 528,145 & 51 \\
\hline Rome & $1,098,172$ & $1,255,450$ & 29 & $1,286,231$ & 51 & $1,300,482$ & 70 & $1,369,044$ & 122 & $1,538,633$ & 239 \\
\hline Genoa & 241,820 & 255,094 & 13 & 266,937 & 24 & 268,541 & 32 & 314,083 & 67 & 42,809 & 20 \\
\hline Naples & 328,116 & 426,327 & 14 & 488,314 & 27 & 536,292 & 37 & 690,830 & 92 & 778,587 & 125 \\
\hline Palermo & 174,490 & 184,940 & 7 & 194,030 & 14 & 195,983 & 17 & 255,659 & 82 & 224,744 & 43 \\
\hline
\end{tabular}


A.G. Calafati and P. Veneri, Re-defining the Boundaries of Major Italian Cities.

Tab. 1b - Major Italian Cities and their Territorial Organisation

\begin{tabular}{|c|c|c|c|c|c|c|c|c|c|c|c|}
\hline & Main municipality & (a) $+1^{\text {st }}$ ring & unicip. & (b) +2 & cing munic. & LLS & & & & MA & \\
\hline & (a) & (b) & n.* & (c) & n. & (d) & n. & (e) & n. & $(\mathrm{f})$ & n. \\
\hline & & & & Area & are kilometre. & & & & & & \\
\hline Turin & 130.2 & 414.1 & 14 & 889.2 & 38 & $1,879.0$ & 88 & 6,824 & 315 & $4,041.4$ & 215 \\
\hline Milan & 182.1 & 406.5 & 22 & 727.4 & 45 & $1,348.3$ & 115 & 1,983 & 189 & $5,169.7$ & 499 \\
\hline Bologna & 140.7 & 623.1 & 10 & $1,379.6$ & 21 & $2,046.7$ & 32 & 3,705 & 60 & $3,390.1$ & 56 \\
\hline Florence & 102.4 & 404.6 & 6 & $1,045.9$ & 14 & $1,262.8$ & 19 & 3,515 & 44 & $3,407.5$ & 51 \\
\hline Rome & $1,285.3$ & $2,461.7$ & 29 & $3,276.9$ & 51 & $3,661.1$ & 70 & 5,343 & 122 & $10,767.6$ & 239 \\
\hline Genoa & 243.6 & 540.6 & 13 & 759.1 & 24 & 930.4 & 32 & 1,840 & 67 & 517.5 & 20 \\
\hline Naples & 117.3 & 241.9 & 14 & 434.3 & 27 & 565.0 & 37 & 1,171 & 92 & $1,746.9$ & 125 \\
\hline Palermo & 158.9 & 854.6 & 7 & $1,135.2$ & 14 & $1,176.4$ & 17 & 4,989 & 82 & $2,169.3$ & 43 \\
\hline & & & & ty (popula & $n$ per square & ometre) & & & & & \\
\hline Turin & $6,647.2$ & $3,066.2$ & 14 & $1,670.2$ & 38 & 896.4 & 88 & 317.4 & 315 & 494.9 & 215 \\
\hline Milan & 6,899.6 & $4,556.8$ & 22 & $3,322.1$ & 45 & $2,207.0$ & 115 & $1,869.5$ & 189 & $1,015.5$ & 499 \\
\hline Bologna & $2,637.8$ & 866.7 & 10 & 467.9 & 21 & 353.4 & 32 & 247.0 & 60 & 267.8 & 56 \\
\hline Florence & $3,477.4$ & $1,343.3$ & 6 & 625.7 & 14 & 536.3 & 19 & 265.7 & 44 & 351.3 & 51 \\
\hline Rome & $1,981.5$ & $1,264.6$ & 29 & $1,005.3$ & 51 & 921.7 & 70 & 692.6 & 122 & 403.0 & 239 \\
\hline Genoa & $2,505.4$ & $1,243.8$ & 13 & 944.2 & 24 & 777.8 & 32 & 477.2 & 67 & 237.5 & 20 \\
\hline Naples & $8,565.7$ & $6,434.6$ & 14 & $4,626.5$ & 27 & $3,957.2$ & 37 & $2,612.5$ & 92 & $2,010.8$ & 125 \\
\hline Palermo & $4,322.3$ & 923.7 & 7 & 744.0 & 14 & 727.8 & 17 & 247.7 & 82 & 490.0 & 43 \\
\hline
\end{tabular}

Columns with 'n.' indicate the number of municipalities that are included in each specific territorial aggregate 
A glance at Table 1 suffices to discern two fundamental features of the Italian territories surrounding the cities examined in this paper. Firstly to be noted is how small the municipalities contiguous to the Italian largest cities are - in terms of population and territorial extension - compared to the corresponding pivotal cities. Secondly to be noted is how numerous are the municipalities in the first and second rings - and in any corresponding functional territorial unit (LLSs, FURs). These features raise two questions which will be discussed later in the paper: a) the very low distance separating the urban settlements located in the first and second rings from the 'focal points' of the pivotal city; b) the marked difference in the strengths of the 'focal points' in the pivot city - in terms of scale, variety and quality of the 'goods' offered - when compared to the focal points located in the first and second rings.

The case of Milan - Fig. 3 - can be taken to exemplify some of the questions raised above. The LLS of Milan, as defined by ISTAT, is composed of 115 municipalities, while the corresponding metropolitan area (FUR) and the corresponding province comprise 499 municipalities and 189 municipalities, respectively. The city de facto identified by the cluster of municipalities made up by the legal city and the municipalities in the first and second rings counts 45 'small' units. ${ }^{16}$ The city de facto appears significantly smaller in terms of territorial extension than the two other functional aggregates (LLS and FUR) in which it is embedded.

A similar pattern of relationships between the city de jure and the corresponding functional urban area, although constrained by its geography, is exhibited by Naples - the third largest city (and metropolitan area) in Italy (Fig. 4). In this case, the first and second rings comprise 26 municipalities - all embedded in the corresponding LLS, which, in its turn, is embedded in the metropolitan area (the LLS and the FUR of Naples count 37 and 125 municipalities, respectively).

\footnotetext{
${ }^{16}$ It should be stressed that a NUTS-3 ('Province') spatial definition - given its administrative nature - never matches, not even broadly, 'functional aggregates' (see Fig. 3 and Table 1). Among the eight cities considered here, in four cases (Milan, Naples, Florence and Rome) the corresponding 'metropolitan area' (FUR) is bigger in terms of population than the province, while in the other four cases the opposite is the case.
} 
Fig. 3 Different spatial aggregates in the case of Milan

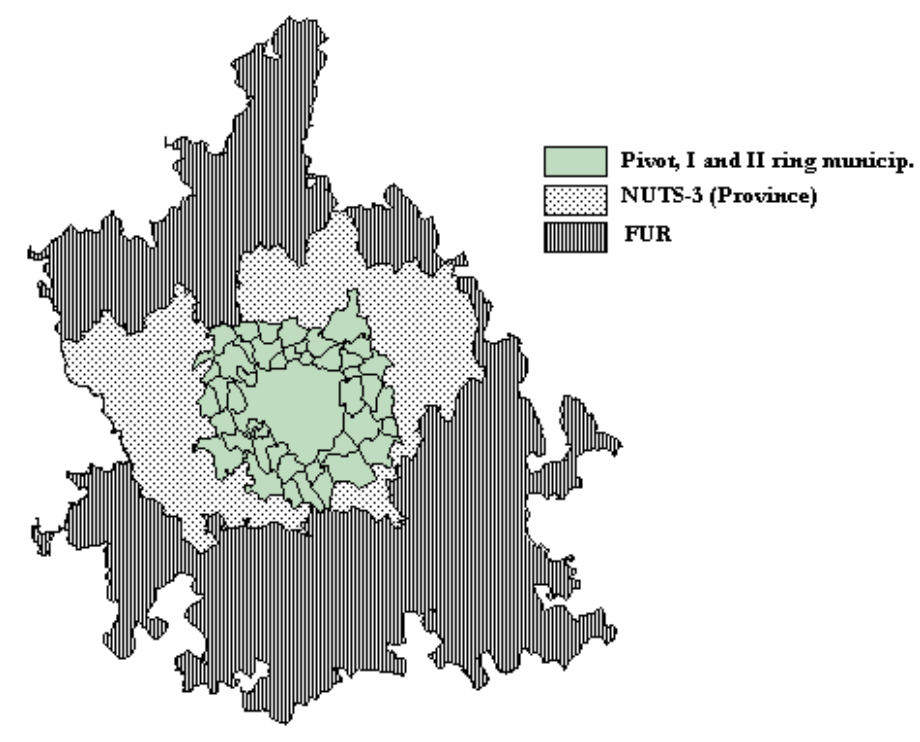

Fig. 4 Different spatial aggregates in the case of Naples

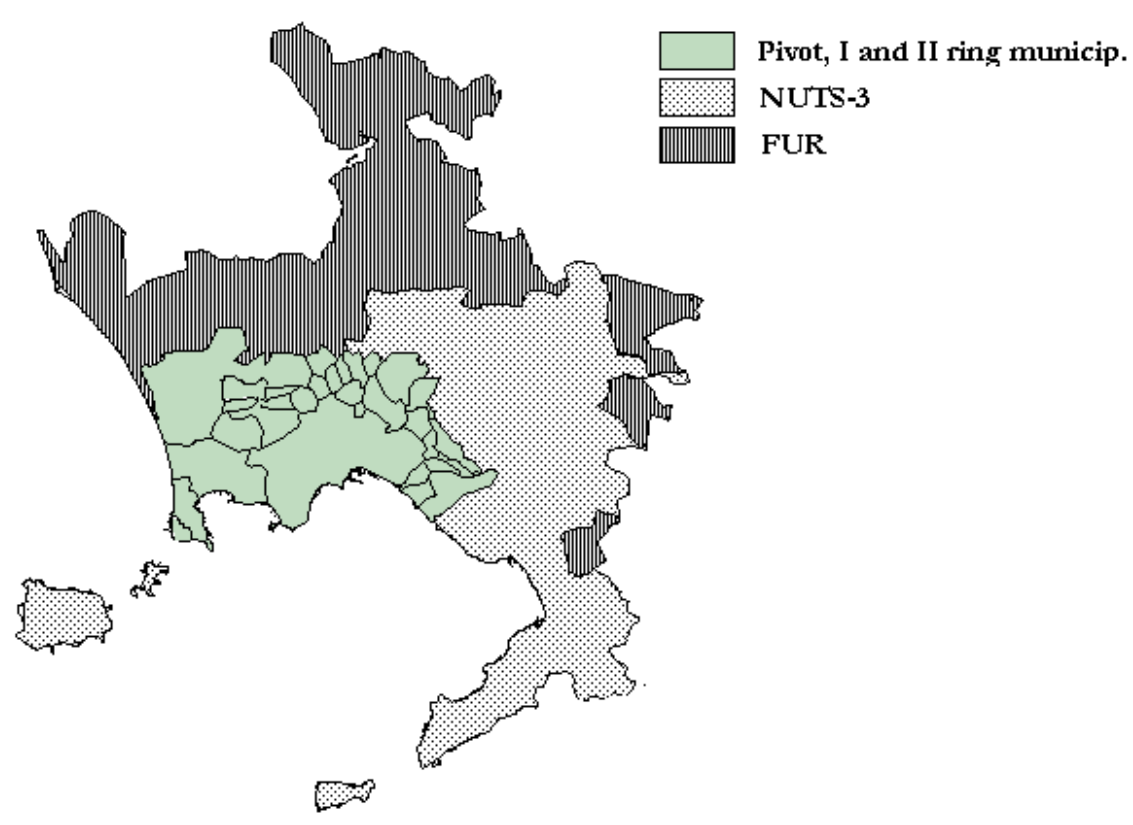

The fact that the municipalities contiguous to the Italian cities examined in this paper are embedded in their relative functional urban areas - LLS or FUR 
- prompts the question of the nature of the integration between these municipalities - first and second rings - and the corresponding cities de jure (pivot).

\section{Identifying the new cities in Italy: corroborating the hypothesis}

In order to corroborate the hypothesis put forward in the previous section we now discuss some empirical evidence concerning the current organisation and its recent changes - of the territorial functional areas associated with the eight largest Italian cities. The types of empirical evidence examined are (a) distances between urban settlements, (b) changes in the spatial distribution of population and employment, (c) commuting-to-work patterns and (d) residential and employment density patterns.

The first step of the analysis is investigation of the first- and second-ring municipalities of the eight largest Italian cities in terms of their 'distance' from the legal cities (see Fig. 5). We shall show that, in all cases, first- and secondring municipalities lie well within the distance normally travelled by Italian urban dwellers on a daily basis. Consequently, they may be parts (neighbourhoods) of the same city.

In this regard, it is necessary to qualify the concept of 'distance'. Firstly, one must refer to distance in this context as a 'cultural', not 'geometric', concept. Travel time, propensity to move, and technology of mobility are more relevant than physical distance when identifying the 'distance' from two points on a territory. Secondly, the relevant distance is the one separating the most important 'focal points' of the territory under scrutiny. Large cities have numerous focal points, and some of them are closer to the urban settlements located in the first- ${ }^{\mathrm{t}}$ and second-ring municipalities than to the city centre (Fig. $5)$.

Figure 5 City de jure, city de facto and focal points

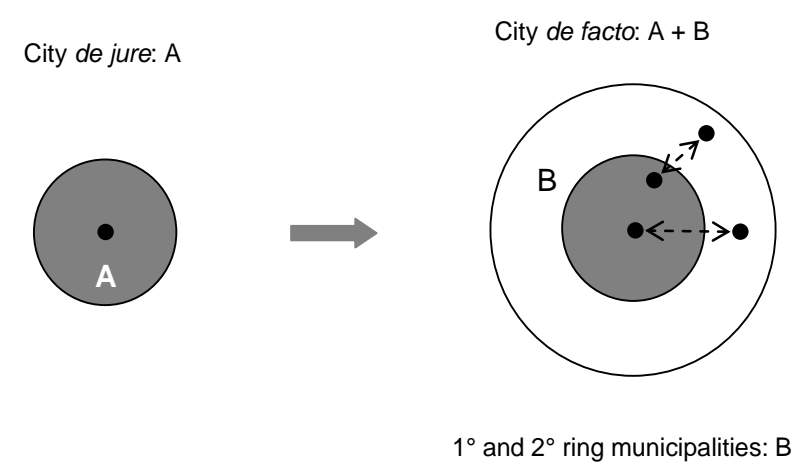

Distance is important for our analysis because it constrains peoples' circadian cycles and, therefore, the spatiality of their transaction patterns. As a 
consequence of mass car use, improvements in public transport and increases in transport infrastructures, there has been an increase in the average distances travelled by individuals on a daily basis. Karlsson and Olsson (2006, p. 1) state that the daily average distance travelled by Swedish people increased from half a kilometre in 1900 to 45 kilometres in 1999. Moreover, as highlighted by Bretagnolle et al. (1999) and by Camagni, Gibelli, Rigamonti (2002, p. 28), increases in daily average distances have not be accompanied by increases in journey duration.

As to the length of the circadian cycles in the Italian cities, we might consider the threshold of 25 kilometres, which, according to a recent survey by Censis (2008), is the daily average distance travelled by Italians. Since this value is an estimate of the entire Italian population, it seems reasonable to assume that in large cities - like those examined here - the daily average distance is more than 25 kilometres.

Table 2 (a) shows the average physical distances from the city centre of each pivot to the city centres of their first- and second-ring municipalities. With the sole exception of Rome, which is distinguished by the unusually large size of its pivotal municipality, all the first-ring municipalities lie well within the territory identified by a 25-kilometre circadian cycle - which, as pointed out above, is a very cautious estimate of the distance travelled daily by the dwellers of the large Italian cities. The same applies to the second-ring municipalities - with the sole exceptions of Genoa and Palermo, whose average distances from the pivot anyway never exceed 30 kilometres.

Better understanding of the actual physical distances that, on average, separate agents in the rings from the city centre of the pivot municipality can be gained from the last three columns in Table 2 (a), which show the 'virtual distances' from the pivot. The term 'virtual distance' refers to the average distance between the centre of pivots and the centre of each ring municipality minus the length of the ring municipalities' geometrical radius. ${ }^{17}$ This is a better approximation of the distance from the first and second rings to the 'focal points' of the pivot cities.

Inspection of these 'virtual distances' shows that, with the expected exception of Rome, both first- and second-ring municipalities can be considered parts of their corresponding city de facto on the basis of the abovementioned threshold of 25 kilometres. We may conclude our analysis of 'cultural' distance by stating that, in principle, the territory of the first and second rings of the eight Italian largest cities is likely to be part of the corresponding city de facto because it lies within what is the usual areal of individuals in modern society.

${ }^{17}$ The length of municipalities' radiuses have been approximated by computing the square root of municipalities' surface; it has thus been hypothesised that municipalities are circular in form. Considering the radius, which takes the form of a straight line, is a prudent way to approximate the shortest distance to the centre. In fact, the road distance to the border of each municipality is certainly higher than the point-to-point one. 
On the basis of these findings on 'distance' in the functional urban areas of the Italian largest cities, we may now proceed with the corroboration by using the available empirical evidence on the basis of the causal meta-model illustrated in Fig. 6.

We may start by observing the intensity of the inter-municipal flows of commuters - both to workplaces and to commercial and socialisation sites - in the territorial systems we consider to be cities de facto and the extent to which these flows increased in the period 1980-2000. However, Italy started to collect data of this kind in the 1981 Census. The available data consequently do not measure the change in the commuting-to-work flows in the decades 1950-1980 - the decades during which the most profound territorial transformation occurred in these territories.

Fig. 6 - The formation of cities de facto in Italy: an explanatory framework

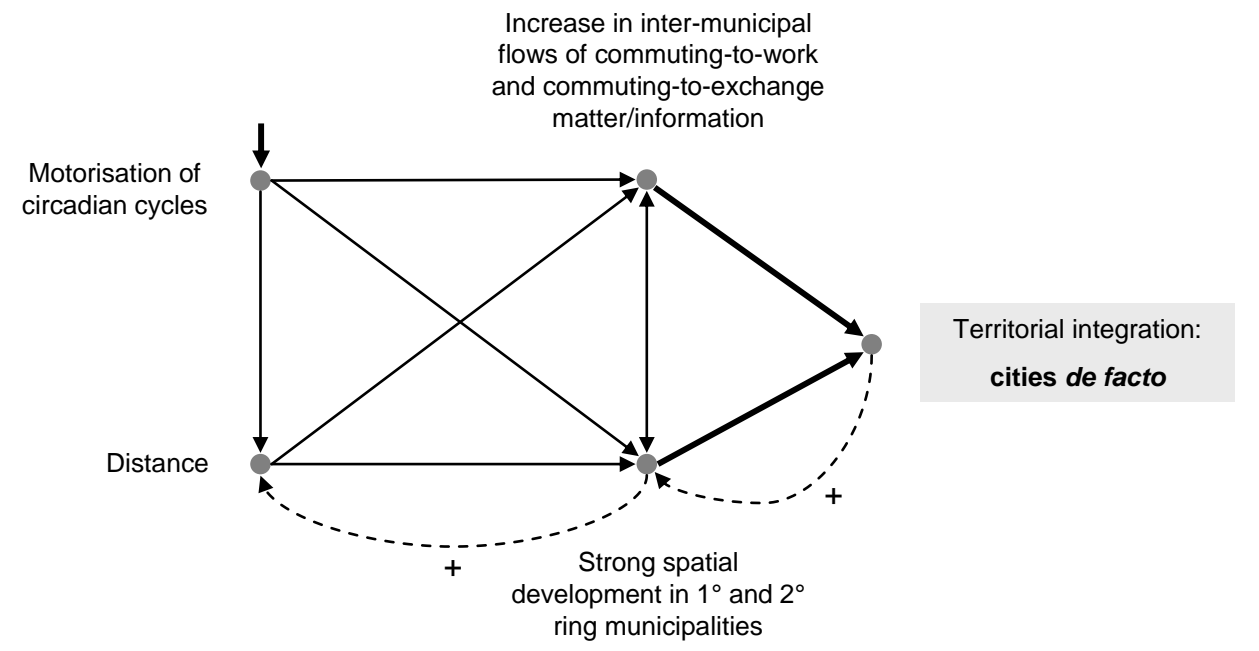

As measures of the current functional interconnections among the municipalities of the territory we take travel-to-work flows. The fourth column of Table 2 (c) shows the share of people that live and work within the city de facto (pivot plus first- and second-ring municipalities). The fifth column considers only people who live in the pivot and in the first ring and who also work in that same area. In all the cities examined, this index has values very close to 1 , which suggests a strong pattern of interaction within each spatial aggregate. At the same time, the degree of autonomy of each municipality in terms of employment (see Tab 2, (c)). The majority of people who live in the rings work in the pivot, where the bulk of employment is located. In this sense, ring municipalities can be regarded as neighbourhoods of the same city, since their main activities take place in the pivot, which is close enough to be the major node where almost every map of individuals' territorial strategy intersects. 
A.G. Calafati and P. Veneri, Re-defining the Boundaries of Major Italian Cities.

The shares of people living and working in the first ring municipalities range from 28\% (Milan) to 39\% (Rome and Palermo). If we consider, instead, the shares of people living in the second-ring municipalities, we have values ranging from 31\% (Milan) to 53\% (Palermo). Comparison between these data and the degree of self-containment of each city (Table 2 (c), fourth column) highlights that first - and to a lesser extent second - ring municipalities are rather strongly integrated with the territory of the pivot municipality in functional terms. Again, this functional pattern of interaction, taken together with the territorial development trajectories previously discussed, is consistent with the hypothesis that ring municipalities are parts of a single wider city de facto. 
Tab. 2 - Major Italian “Cities de facto": some data

a) Distances (Kilometres)

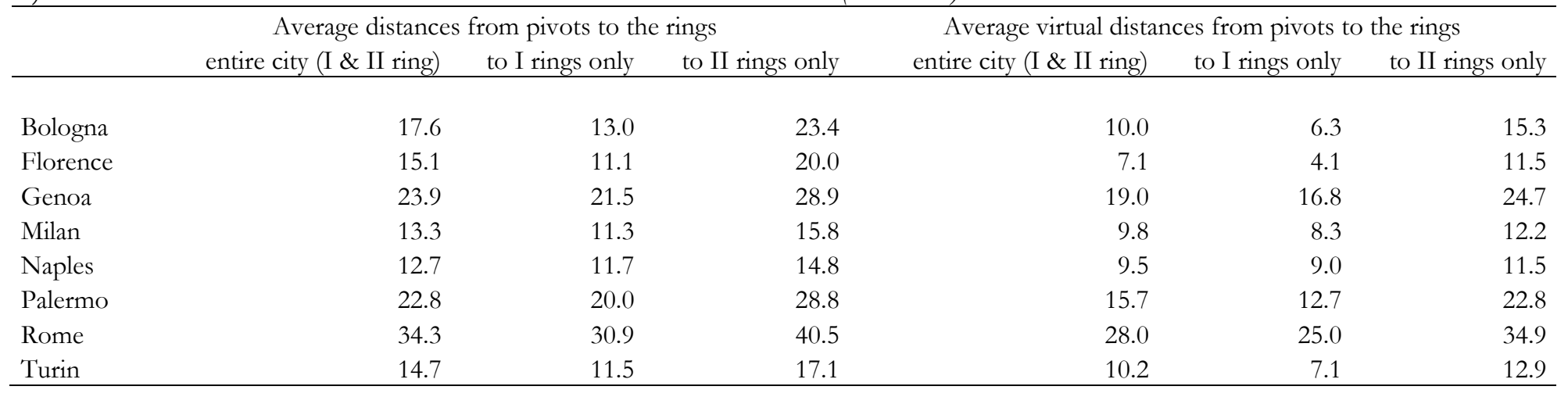

\begin{tabular}{|c|c|c|c|c|c|c|c|c|}
\hline \multirow[t]{3}{*}{ b) } & \multicolumn{8}{|c|}{ Population and employment variations (1951-2001) - val. \% } \\
\hline & \multicolumn{4}{|c|}{ var. pop. 1951-2001 } & \multicolumn{3}{|c|}{ var. empl. 1951-2001 } & \multirow[b]{2}{*}{ entire city } \\
\hline & pivot & I ring & II ring & entire city & pivot & I ring & II ring & \\
\hline Florence & -4.9 & 108.3 & 33.2 & 19.5 & 33.7 & 506.2 & 297.2 & 97.3 \\
\hline Genoa & -11.4 & 15.9 & 20.7 & -8.0 & -20.3 & 73.2 & 58.6 & -15.5 \\
\hline Milan & -1.4 & 283.7 & 176.5 & 47.9 & -2.8 & 313.4 & 257.9 & 44.0 \\
\hline Palermo & 39.9 & 69.7 & 29.6 & 42.2 & 61.8 & 106.8 & 237.1 & 69.9 \\
\hline Rome & 54.2 & 247.3 & 154.3 & 74.7 & 115.7 & 562.9 & 337.8 & 143.1 \\
\hline Turin & 20.3 & 253.7 & 171.0 & 62.6 & -8.8 & 373.6 & 366.2 & 40.9 \\
\hline
\end{tabular}


A.G. Calafati and P. Veneri, Re-defining the Boundaries of Major Italian Cities.

Tab. 2 - Major Italian “Cities de facto": some data

\begin{tabular}{|c|c|c|c|c|c|}
\hline \multirow[t]{3}{*}{ c) } & \multicolumn{5}{|c|}{ Functional integration } \\
\hline & \multicolumn{3}{|c|}{$\begin{array}{l}\text { Share of commuters that live and work in the same } \\
\text { municipality }\end{array}$} & \multicolumn{2}{|c|}{ Share of commuters that live and work in the same area } \\
\hline & pivot & I ring & II ring & within the entire city* & within I ring \\
\hline Bologna & 0.76 & 0.31 & 0.35 & 0.94 & 0.90 \\
\hline Florence & 0.78 & 0.33 & 0.36 & 0.92 & 0.89 \\
\hline Genoa & 0.95 & 0.29 & 0.36 & 0.97 & 0.96 \\
\hline Milan & 0.82 & 0.28 & 0.31 & 0.91 & 0.88 \\
\hline Naples & 0.86 & 0.36 & 0.40 & 0.91 & 0.89 \\
\hline Palermo & 0.95 & 0.39 & 0.53 & 0.97 & 0.96 \\
\hline Rome & 0.95 & 0.39 & 0.34 & 0.98 & 0.98 \\
\hline Turin & 0.79 & 0.29 & 0.32 & 0.93 & 0.89 \\
\hline
\end{tabular}

d)

Densities (population per square kilometre)

\begin{tabular}{|c|c|c|c|c|c|c|}
\hline & \multicolumn{3}{|c|}{ Average densities within cities } & \multicolumn{3}{|c|}{ Density variation within cities (1951-2001) - val. \% } \\
\hline & density pivot & av. density I ring & av. density II ring & Pivot & & II ring \\
\hline Bologna & $2,637.8$ & 499.6 & 147.7 & 9.0 & 155.6 & 25.5 \\
\hline Florence & $3,477.4$ & 676.2 & 258.4 & -4.9 & 110.1 & 42.5 \\
\hline Genoa & $2,505.4$ & 276.9 & 338.1 & -11.4 & 15.2 & 34.7 \\
\hline Milan & $6,899.6$ & $3,169.6$ & $1,973.2$ & -1.4 & 306.5 & 199.6 \\
\hline Naples & $8,565.7$ & $6,607.1$ & $3,873.1$ & -0.6 & 201.5 & 111.0 \\
\hline Palermo & $4,322.3$ & $1,099.3$ & 357.5 & 39.9 & 130.0 & 65.0 \\
\hline Rome & $1,981.5$ & 630.8 & 268.6 & 54.2 & 204.2 & 122.3 \\
\hline Turin & $6,647.2$ & $1,487.5$ & 489.6 & 20.3 & 294.8 & 184.4 \\
\hline
\end{tabular}


The Italian industrial take-off - and the ensuing strong polarisation of the economic process - took place during the first three decades after the Second World War. The highest increases in employment and population experienced by the functional urban areas examined occurred during those decades. In particular, the most remarkable increases were recorded by the first- and second-ring municipalities of the cities examined. Given the motorisation of the circadian cycles that made a substantial extension of the cycles themselves possible, these patterns of spatial development can be explained by the 'short' distance, as discussed above, from the focal points of the pivotal cities to the focal points of the surrounding territory.

Table 2 (b) shows population and employment growth rates between 1951 and 2001 in the pivots, and in the municipalities located in their first and second rings. To be noted is that, while some pivots have experienced both population and employment decreases, municipalities located in the first and second rings have always recorded population and employment increases. Moreover, it can be observed that, with the sole exceptions of Genoa and Palermo, first-ring municipalities almost always display higher growth rates than second-ring municipalities. These findings are consistent with the thesis that pivot municipalities have expanded their territories as well as their areas of influence. The fact that some of them have experienced a reduction in employment and population, whereas first- and second-ring municipalities have always grown, together with the consideration that ring municipalities are located within a distance where daily urban circadian cycles occur, is consistent with the hypothesis that cities de facto, in the cases under scrutiny, are much larger than their corresponding pivotal, legal cities. ${ }^{18}$ If one does not consider the existing legal boundaries, the territorialisation of the economic and social process can be interpreted as a process of 'city construction', accompanied by a new spatial organisation. This dispersion of cities in space is the standard spatial development trajectory so often observed in the history of cities, especially since mass motorization (see Secchi, 2005; Bruegman, 2005).

The same point can be highlighted by looking at changes in population density within each city. Although residential density in absolute terms differs significantly among the eight cities examined, in 2001 each of them shows values of residential density which decrease smoothly with the distance from the pivot municipality (Tab. 2, (d)). Figure 7 illustrates this pattern in the case of Turin, which is consistent with the simple negative exponential density function proposed by Clark (1951), and with the idea of the monocentric urban spatial organisation. In fact, on moving away from the city centre, no particularly high residential-density place is to be observed. In particular, no density peaks seem to emerge in the proximity of the external border of the city.

${ }^{18}$ Much larger because, by including first- and second-ring municipalities, population increases by $37 \%$, on average and territory by more than $300 \%$. 
This empirical evidence gained by examining the residential density function supports the idea that cities de facto are organised around one single centre (the pivot) and that no other urban centrality exists in their pertaining territories. Hence, the areas examined possess only one centre of power. This may not be the case if one considers metropolitan areas, where polycentric patterns of development may be present (Veneri, 2009).

Fig. 7 Residential density and distance from the pivot in 1951 and 2001 - Turin

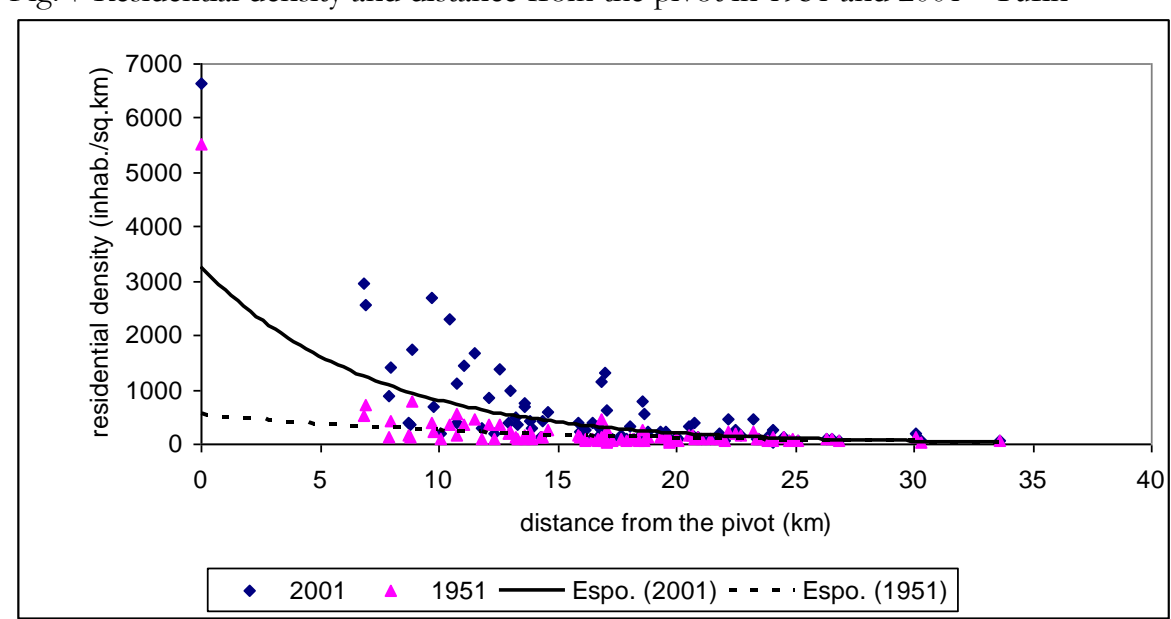

Source: our calculations on Istat Population Census, 1951 and 2001

Changes in residential densities between 1951 and 2001 occurred especially in the municipalities close to the pivots (Table 2 (d)). In fact, the increase in the density of first- and - to a lesser extent - second-ring municipalities made the 2001 density function higher than that of the 1950s (Fig. 7). Figure 7 plots the relation between residential densities and distance from the pivot municipality in the case of Turin (all the municipalities belonging to the same LLS). From the figure it is possible to note that the density gradient in 2001 was steeper than in 1951, especially for municipalities closer to the centre. This finding seems consistent with idea of the formation - in the five decades considered of wider cities through a process of territorial coalescence.

\section{CONCLUDING REMARKS}

Italian metropolises were 'unbound' as a result of factors commonplace in the recent urban history of advanced countries. However, given the features of the Italian territory, in order to expand their territory, the largest cities had physically and relationally to incorporate neighbouring communities - turning legal cities into inappropriate units for analysis and policy intervention.

The paper has addressed the question of the appropriateness of the extant boundaries of the largest Italian cities since the 'territorial revolution' that profoundly changed the spatial organisation of the social process. Despite 
some minor differences among the cities analysed, we believe that we have corroborated our central thesis, namely that, in the cases analysed, the cities de facto are significantly larger than the corresponding current cities de jure, in that they extend at least over the territory of the first- and second-ring municipalities.

Our first conclusion is that the Italian urban system can no longer be represented by taking current cities de jure as the units of analysis. In so doing, one obtains a mistaken representation of the Italian urban landscape. It is simply meaningless to compare the performances of Rome and Berlin, Turin and Munich, Milan and Hamburg - to cite just a few examples - if one takes, in the case of Italian cities, the current legal borders. Our understanding of territorial performances in Italy, and the outcome of any comparative exercise at the national and European scale, is distorted. However, once researchers are aware of this problem, while awaiting the required institutional change, they may circumvent the problem by using - as a suggested in this paper - different units of analysis to explore the Italian urban system.

From a normative perspective the question raised in this paper is more complex. For some decades now, the spatial organisation of the policy-making process has not matched the spatial organisation of Italian society - and this state of affairs may be deemed responsible for many disequilibria of Italy's most important cities. As highlighted in the paper, the discrepancy between the institutional and territorial organisation of the territory is so large that profound reform of the political system is urgently needed. This would amount to a long-overdue change in the institutional fields within which agency takes form in Italian cities and urban development trajectories unfold - a question of great significance against the background of the strategic role that cities are asked to perform in the European space and of the increasing decentralisation of political power in Europe.

\section{REFERENCES}

Bartaletti F. (1992), Principi e metodi di delimitazione delle aree metropolitane, Studi e ricerche di geografia, Vol. 15(2), pp. 80-100.

Becattini G. (1979), Dal settore industriale al distretto industriale. Alcune considerazioni sull'unità di indagine dell'economia industriale, Rivista di Economia e Politica Industriale, Vol. 1, pp. 35-48.

Boix R. and Veneri P. (2009), Metropolitan areas in Spain and Italy, IERMB Working Paper in Economics, $\mathrm{n}^{\circ} 09.01$ - Institut d'Estudis Regionals i Metropolitans de Barcelona.

Bretagnolle A., Degorge-Lavagne M. and Pumain D. (1999), La ville et la croissance dans l'espace-temps, Mappemonde, Vol. 55(3), pp. 38-42.

Bruegmann R. (2005), Sprawl: a compact history, The University of Chicago Press, Chicago. 
A.G. Calafati and P. Veneri, Re-defining the Boundaries of Major Italian Cities.

Brunel D. (2002), Economic Performance of the European Regions, Papers of the Institut à Aménagement et d'Urbanisme de la Région Ile de France (IAURIF), No. 135, Paris.

Cafiero S. and Busca A. (1970), Lo sviluppo metropolitano in Italia, Giuffré, Naples.

Cainelli G., Iacobucci D. and Morganti E. (2006), Spatial agglomeration and business groups: New evidence from Italian industrial districts, Regional Studies, Vol. 40(5), pp. 507-518.

Calafati A.G. (2002), Sistemi locali: esercizi di identificazione in L. Malfi and D. Martellato (eds.), Il ruolo del capitale nello sviluppo locale e regionale, Franco Angeli, Milan.

Calafati A.G. (2005), On the use of Local Labour Systems, Scienze Regionali/Italian Journal of Regional Science, Vol. 4(1), pp. 139-144.

Calafati A.G. (2009a), Economie in cerca di città. La questione urbana in Italia, Donzelli, Rome.

Calafati A.G. (2009b), Macro-regions, Local systems, and Cities: The Conceptualisation of Territory in Italy since 1950, Scienze Regionali/Italian Journal of Regional Science, Vol. 8(3) (Supplement), pp. 11-34.

Calafati A.G. and Mazzoni F. (2008), Città in nuce nelle Marche. Coalescenza territoriale e sviluppo locale, Franco Angeli, Milan.

Camagni R. and Lombardo S. (eds.) (1999), La città metropolitana: strategie per il governo e la pianificazione, Alinea, Florence.

Camagni R., Gibelli M.C. and Rigamonti P. (2002), I costi collettivi della città dispersa, Alinea, Florence.

Cecchini D. (1989), Le aree urbane in Italia: scopi, metodi e primi risultati di una ricerca, Rivista economica del Mezrogiorno, anno $2^{\circ}$, n.1.

Censis (2008), Pendolari d'Italia. Scenari e strategie. Franco Angeli, Milan.

Clark C. (1951), Urban population densities, Journal of the Royal Statistical Society, Series A, Vol. 114, pp. 490-496.

Compagnucci F. (2009), L'interpretazione dell'organizzazione territoriale del processo economico in Italia: concetti, metodi, analisi e proposte, Ph.D. Thesis, Marche Polytechnic University, Ancona.

Costa P. e Toniolo M. (eds.) (1992), Città metropolitane e sviluppo regionale, Franco Angeli, Milan.

European Union (2007), State of the European Cities Report. Adding Value to the European Urban Audit, Ecotec Research and Consulting Ltd., Brussels.

Ferlaino F. and Molinari P. (2009), Neofederalismo, neoregionalismo e intercomunalità, Il Mulino, Bologna.

Geddes P. (1915), Cities in Evolution, Williams and Norgate, London.

Hall P. (2009), Looking Backward, Looking Forward: The City Region of the Mid-21st Century, Regional Studies, Vol. 43(6), pp. 803-817.

Karlsson C. and Olsson M. (2006), The identification of functional regions: theory, methods and applications, Annals of Regional Science, Vol. 40(1), pp. $1-18$.

ISTAT-IRPET (1989), I mercati locali del lavoro, Franco Angeli, Milan. 
A.G. Calafati and P. Veneri, Re-defining the Boundaries of Major Italian Cities.

ISTAT (1997), I sistemi locali del lavoro 1991, Istat, Rome.

ISTAT (2005), Distretti industriali e sistemi locali del lavoro 2001, Istat, Rome.

ISTAT (2008), Rapporto annuale: la situazione del paese al 2007, Istat, Rome.

Lang R. and Knox P.K. (2009), The New Metropolis: Rethinking Megalopolis, Regional Studies, Vol. 43(6), pp. 789-802.

Marchese U. (1997), Aree metropolitane in Italia alle soglie del duemila, ECIG, Naples.

Martinotti G. (eds.) (1999), La dimensione metropolitana, Il Mulino, Bologna.

Office of Management and Budget (1990), Revised standards for defining metropolitan areas in the 1990s, Federal Register, Vol. 55, pp. 12154-12160.

Parr J.B. (2005), Perspectives on the city-regions, Regional Studies, Vol. 39(5), pp. 555-566.

Parr J.B. (2007a), Spatial Definitions of the City: Four Perspectives, Urban Studies, Vol. 44(2), pp. 381-392.

Parr J.B. (2007b), On the spatial structure of administration, Environment and Planning A, 39(5), pp. 1255-1268.

Parr J.B. (2008), Cities and regions: problems and potentials, Environment and Planning A, 40(12), pp. 3009-3026.

Secchi B. (2005), La città del XX secolo, Laterza, Rome.

Signorini F.L. (2000), Lo sviluppo locale. Un'indagine della Banca d'Italia sui distretti industriali, Meridiana, Rome.

Veneri P. (2009), Policentrismo urbano e costi sociali della mobilità nelle aree metropolitane italiane, Ph.D. Thesis, Marche Polytechnic University, Ancona.

Vitali O. (1990), Mutamenti nelle aree urbane. Popolazione e occupazione dal 1951 al 1987, Franco Angeli, Milan.

Waddington C.H. (1977), Tools for thought, Jonathan Cape Ltd, London.

Zimmermann C. (1996), Die Zeit der Metropolen, Fischer Taschenbuch Verlag $\mathrm{GmbH}$, Frankfurt. 